\title{
Mosquito Akirin as a potential antigen for malaria control
}

\author{
Mário da Costa', Renato Pinheiro-Silva', Sandra Antunes', Juan A Moreno-Cid ${ }^{2}$, Ana Custódio ${ }^{1,4}$, Margarita Villar ${ }^{2}$, \\ Henrique Silveira ${ }^{1,4}$, José de la Fuente ${ }^{2,3}$ and Ana Domingos ${ }^{1,4^{*}}$
}

\begin{abstract}
Background: The control of vector-borne diseases is important to improve human and animal health worldwide. Malaria is one of the world's deadliest diseases and is caused by protozoan parasites of the genus Plasmodium, which are transmitted by Anopheles spp. mosquitoes. Recent evidences using Subolesin (SUB) and Akirin (AKR) vaccines showed a reduction in the survival and/or fertility of blood-sucking ectoparasite vectors and the infection with vector-borne pathogens. These experiments suggested the possibility of using AKR for malaria control.

Methods: The role of AKR on Plasmodium berghei infection and on the fitness and reproduction of the main malaria vector, Anopheles gambiae was characterized by evaluating the effect of akr gene knockdown or vaccination with recombinant mosquito AKR on parasite infection levels, fertility and mortality of female mosquitoes.

Results: Gene knockdown by RNA interference in mosquitoes suggested a role for akr in mosquito survival and fertility. Vaccination with recombinant Aedes albopictus AKR reduced parasite infection in mosquitoes fed on immunized mice when compared to controls.

Conclusions: These results showed that recombinant AKR could be used to develop vaccines for malaria control. If effective, AKR-based vaccines could be used to immunize wildlife reservoir hosts and/or humans to reduce the risk of pathogen transmission. However, these vaccines need to be evaluated under field conditions to characterize their effect on vector populations and pathogen infection and transmission.
\end{abstract}

Keywords: Akirin, Arthropod, Mosquito, Subolesin, Vaccine, Malaria

\section{Background}

Malaria, one of the world's deadliest diseases, is caused by protozoan parasites of the genus Plasmodium which are transmitted by Anopheles spp. mosquitoes [1]. Last malaria report from WHO, estimates that 3.4 billion people were at disease risk in 2013 [2]. Plasmodium spp. have a complex multi-stage life cycle involving two hosts, primary host (mosquito) and secondary host (human) occurring in different cellular environments [3].

Recently, methodologies for diagnosis and integrated vector control by various physical and chemicals methods have been improved or implemented and research to develop vaccines against malaria is being carried on by

\footnotetext{
*Correspondence: adomingos@ihmt.unl.pt

${ }^{1}$ Instituto de Higiene e Medicina Tropical, Rua da Junqueira 100, 1349-008

Lisbon, Portugal

${ }^{4}$ Centro de Malária e Outras Doenças Tropicais, Instituto de Higiene e

Medicina Tropical, Rua da Junqueira 100, 1349-008 Lisbon, Portugal

Full list of author information is available at the end of the article
}

several groups around the world [3]. The development of a vaccine against malaria has been a difficult task, mainly due to the complexity of the parasite life cycle and the equally complex and multifaceted host immune responses [4]. Malaria vaccines targeting the blood stage are considered as anti-disease vaccines as they prevent or reduce clinical disease but do not prevent infection [4]. An efficacious pre-erythrocytic vaccine would block disease by inhibiting parasites to reach the blood stream and preventing transmission. The RTS,S/AS is an example of a candidate pre-erythrocytic vaccine at phase III field trials performed in eleven African research centres [5,6]. However, the first results from these trials were not as good as expected [7]. Recently, another pre-erythrocytic candidate vaccine based on whole attenuated sporozoites has been developed; phase I trials were concluded showing several weaknesses such as the need for intravenous administration of very high number of sporozoites to 
achieve complete immune protection in vaccinated individuals [8]. This could be overcome by transmissionblocking vaccines that specifically intend to target molecules that are exclusive to gametocytes or to other mosquito stages. Antibodies against these targets are capable of blocking the development of parasite sexual stages and, therefore, interrupt transmission. A vaccine based on mosquito-stage proteins of both Plasmodium falciparum and Plasmodium vivax was shown to produce dose-dependent antibody-mediated transmission-blocking activity but showed to be unacceptably reactogenic [9].

Preliminary results obtained in arthropod vectors with impact on human and animal health have shown that protective antigens may be used for the development of vaccines against both vectors and pathogens they transmit [10-18]. Among these antigen candidates, tick Subolesin (SUB) and the ortholog in insects, Akirin (AKR), have been used to induce a protective response in vaccinated hosts for the control of hard (Ixodes spp., Rhipicephalus spp., Amblyomma americanum, Dermacentor variabilis) and soft (Ornithodoros spp.) ticks, mosquitoes (Aedes albopictus), sand flies (Phlebotomus perniciosus), poultry red mites (Dermanyssus gallinae) and sea lice (Caligus rogercresseyi) infestations and tick infection with Anaplasma phagocytophilum, A. marginale, Babesia bigemina and Borrelia burgdorferi [15,19-21]. These results suggest that vaccines based on AKR/SUB antigens could control vector-borne diseases by a dual effect on vector populations and vector capacity $[15,16]$.

SUB/AKR intermediate proteins interactions with NF-kB and other regulatory proteins bind DNA and remodel chromatin to regulate gene expression of signal transduction and innate immune response genes and transcriptional regulators [16,22-24]. This broad function of SUB/AKR as transcription factors explains the profound effect of gene knockdown by RNAi on tick and insect physiology, as well as on development and gene expression in ticks $[15,16]$. SUB and AKR are functionally important for arthropod innate immunity and, at least in ticks, for tissue development and function and for pathogen infection and multiplication [16,25].

A connection between the expression of mosquito AKR and Plasmodium spp. infection has not yet been established. However, several studies linked Anopheles gambiae NF-kB-like transcription factor REL2 to antiparasitic defenses [26,27]. These results together with the need to develop effective vaccines for malaria control have encouraged research on the possibility of using AKR for the control of An. gambiae populations and the infection with Plasmodium parasites.

The role of AKR on Plasmodium berghei infection and on the fitness and reproduction of the main malaria vector, An. gambiae was characterized by evaluating the effect of $a k r$ gene knockdown or vaccination with recombinant mosquito AKR on infection rate, parasite burdens, fertility and mortality of female mosquitoes.

\section{Methods}

\section{Ethical statement}

Animals were housed at the Instituto de Higiene e Medicina Tropical, in strict accordance with the recommendations of the Europe Directive 86/609/ EEC and Portuguese law (Decreto-Lei No. 129/92). Animal experiments were conducted with the approval of the Divisão Geral de Alimentação e Veterinária (DGAV), Portugal, under $\mathrm{Art}^{\circ}$ 8, Portaria $\mathrm{n}^{\circ} 1005 / 92$ from $23^{\text {rd }}$ October (permit number $n^{\circ}$ 023357). At the end of the experiment, mice were anesthetized before being euthanized by cervical disruption.

\section{Mosquitoes}

The An. gambiae s.s. (molecular M form) of the Yaoundé strain mosquitoes were obtained from the Instituto de Higiene e Medicina Tropical (IHMT) insectary and reared at $26^{\circ} \mathrm{C}$ and $75 \%$ humidity on a $12 / 12$ hour light/ dark cycle. Adult mosquitoes were maintained on a $10 \%$ glucose solution.

\section{Anopheles gambiae infection with Plasmodium berghei}

To obtain An. gambiae mosquitoes infected with P. berghei for gene expression and gene knockdown analyses, four weeks old female CD1 mice obtained from the IHMT animal house were intraperitoneally inoculated with $10^{7}$ P. berghei parasitized red blood cells. GFP (PbGFPCON), a recombinant $P$. berghei strain that constitutively expresses GFP in the cytoplasm from a transgene controlled by the elongation factor-1-alpha gene promoter was used [28]. Parasitaemia were determined from blood samples collected from mouse tail, using light microscopy after methanol fixation of air-dried blood smears and staining with $10 \%(\mathrm{w} / \mathrm{v})$ Giemsa. When the parasitaemia reached $10-20 \%$ and exflagellation was observed (4-6 exflagellations/field), mice were used to infect mosquitoes. Female mosquitoes $(\mathrm{N}=200 /$ mice $)$ were allowed to feed directly on $P$. berghei infected mice $(\mathrm{N}=3)$ for 30-45 minutes. Unfed female mosquitoes were removed from the cage. Fully engorged mosquitoes were kept at $19-21^{\circ} \mathrm{C}$ and $80 \%$ humidity for P. berghei development.

\section{Characterization of mosquito akr gene expression after parasite infection}

The $P$. berghei infected and uninfected female mosquitoes were dissected. Midguts and the abdomen carcass (herein after denominated fat body) were stored in ice-cold RNA later (Ambion, Austin, TX, USA). Tissues were used immediately or stored at $-20^{\circ} \mathrm{C}$ until RNA extraction. Pools of 30 infected/uninfected midguts and fat body 
were produced and total RNA was extracted using the Nucleospin RNAII kit (Macherey-Nagel, Bethlehem, USA) following the manufacturer's instructions. First strand cDNA was synthesized using oligo dT and MMLV Reverse Transcriptase (Promega, Madison, USA). The akirin (Vectorbase: AGAP006809) expression levels were determined by qPCR using gene-specific oligonucleotide primers (5'- CCCTGTTCACCTTCAAGCAG-3' and 5'- GGTCAGCACGGCATCATACT-3') and $\mathrm{iQ}^{\mathrm{m}} \mathrm{S}$ SYBR Green supermix in the iCycler iQ ${ }^{\mathrm{mi}}$ (Bio-Rad, Hercules, CA, USA) following the manufacturer's recommendations. Fluorescence readings were taken at $62^{\circ} \mathrm{C}$ after each cycle and a melting curve was obtained to confirm the identity of the PCR product. Experiments were made in triplicate. The mRNA levels were normalized against ribosomal protein S7 gene (RPS7; Vectorbase: AGAP010592) using oligonucleotide primers (5'-GCC ATCCTGGAGGATCTGGTA-3' and 5'-CGATGGTGG TCTGCTGTTCTTATCC-3') and the comparative $\Delta \Delta \mathrm{Ct}$ method [29]. Normalized mRNA levels were compared between infected and control mosquitoes by Student's $t$-test with unequal variance $(\mathrm{P}=0.05)$.

\section{Mosquito akr gene knockdown}

RNAi was used to characterize the effect of $a k r$ gene knockdown in mosquitoes [30,31]. The akr specific primers containing T7 promoter sequences at the 5 '-end were synthesized (Table 1) and using the MEGAscript T7 kit (Ambion, Austin, TX, USA) dsRNA was produced according to manufacturer's instructions. An exogenous gene, mouse beta-2 microglobulin (B2m) (GenBank: NM_009735) was used as control and the dsRNA was synthesized in a similar way (Table 1). The dsRNA was diluted in sterile water to a concentration of $3 \mathrm{mg} / \mathrm{ml}$ and concentration and quality were assessed by spectrometry and agarose gel. For gene knockdown, 600 female mosquitoes were used (200 mosquitoes/mouse). Cold anesthetized three day old-female mosquitoes were injected intrathoraxically with $69 \mathrm{nl}$ of dsRNA using a nanoinjector (Nanoject; Drummond Scientific, Broomall, PA, USA). The control group was injected with $B 2 m$ dsRNA. Four days after dsRNA injection gene knockdown was analyzed by RT qPCR and the remaining mosquitoes were fed on a mouse infected with $P$. berghei and kept as above for parasite development. Surviving mosquitoes were counted and dissected 8 days after feeding. Midguts were mounted on coverslips and oocysts visualized under a fluorescent microscope to determine infection intensity (median number of parasite oocyst per infected mosquito) and the number of eggs in the ovaries. Infection rate (100 $\times$ [number of infected mosquitoes/total number of mosquitoes analysed]) was evaluated. Pools of approximately 30 infected/uninfected midguts and fat body were used to determine $a k r$ mRNA levels by RT-qPCR as described before. Normalized mRNA levels and the number of mosquitoes that survived dsRNA injection were compared between akirin dsRNA-injected and control mosquitoes injected with unrelated $B 2 m$ dsRNA by Student's $t$-test with unequal variance $(\mathrm{P}=0.05)$. The number of parasite oocysts and eggs in mosquito midguts and the number of surviving mosquitoes were compared between $a k r$ dsRNA-injected and control mosquitoes injected with unrelated $B 2 m$ dsRNA by a two-sample comparison using the non-parametric Mann-Whitney test $(\mathrm{P}=0.0001)$.

\section{Mouse immunization and infection challenge}

Recombinant AKR from Ae. albopictus was produced as previously reported using an extractive bioconversion process in an aqueous two-phase system supporting Pichia pastoris growth and protein secretion and used on immunization trials adjuvated in Montanide ISA 50 V2 (Seppic, Paris, France) $[13,17,18]$. Five weeks old female Balb/c mice ( $\mathrm{N}=5$ per group) were obtained from the IHMT animal facility and used for the immunization trial. Mice were immunized intraperitoneally with 4 doses of $0.1 \mathrm{ml}$ each containing $20 \mu \mathrm{g}$ of recombinant AKR emulsified (1:1) with the adjuvant Montanide ISA 50 V2 (Seppic, Paris, France) [22] two weeks apart. Mice were immunized with AKR or adjuvant/saline and then infected with $P$. berghei or left uninfected as control. Two weeks after the last immunization, mice were infected with P. berghei by direct bite of infected mosquitoes. Thirty female mosquitoes, 3-5 days old, fed on each mouse for 30-45 minutes. After infective blood meal, only fully engorged females were transferred to individual vials for oviposition. Egg cups were removed seven

Table 1 Gene-specific primers and conditions used for dsRNA synthesis

\begin{tabular}{|c|c|c|c|}
\hline Gene (accession number) & Upstream/downstream primer sequence $\left(5^{\prime}-3^{\prime}\right)$ & Fragment size (bp) & PCR annealing conditions \\
\hline & $\begin{array}{l}\text { TAATACGACTCACTATAGGGTACTITGGCAGTCGTTGTAGTTGC } \\
\end{array}$ & & \\
\hline \multirow[t]{3}{*}{ Mosquito akirin (AGAP006809) } & & 509 & $52^{\circ} \mathrm{C} / 1 \mathrm{~min}$ \\
\hline & TAATACGACTCACTATAGGGTACTCACCTGCTTGAAGGTGAACA & & \\
\hline & TAATACGACTCACTATAGGGAGACACCCCCACTGAGACTGATACA & & \\
\hline \multirow[t]{2}{*}{ Mouse B2m (NM_009735) } & & 447 & $62^{\circ} \mathrm{C} / 45 \mathrm{sec}$ \\
\hline & TAATACGACTCACTATAGGGAGACACCCCCACTGAGACTGATACA & & \\
\hline
\end{tabular}

T7 promoter sequences (5'-TAATACGACTCACTATAGGGTACT-3') were included at the $5^{\prime}$-end for dsRNA synthesis. 
days post-feed to count laid eggs per mosquito. Mosquito survival at 8 days post-infestation was also evaluated. Infection rate and infection intensity were determined as described before. Mosquito infection challenge was performed in three independent experiments. Results from mosquitoes fed on AKR-immunized and control mice were compared by Student's $t$-test with unequal variance $(P=0.05)$.

\section{Determination of serum antibody levels by ELISA}

Before each immunization and two weeks after the last immunization mouse tail blood was collected to prepare sera for analysis of antibodies titers against AKR by an indirect enzyme-linked immunosorbent assay (ELISA). A high binding 96 well-ELISA plate (Costar ${ }^{\circ}$ MA, USA) was incubated overnight at $4^{\circ} \mathrm{C}$ with $0.1 \mu \mathrm{g}$ of recombinant protein per well diluted in $100 \mu \mathrm{l}$ PBS. After antigen incubation, the plate was washed twice with tris buffered saline $(25 \mathrm{mM}$ Tris $\mathrm{HCl}, 150 \mathrm{mM} \mathrm{NaCl}, 2 \mathrm{mM} \mathrm{KCl})$ containing $0.05 \%(\mathrm{v} / \mathrm{v})$ Tween 20 (TBST), blocked with $200 \mu \mathrm{l}$ of $5 \%(\mathrm{w} / \mathrm{v})$ milk (BioRad, Hercules, CA, USA) at room temperature for one hour and washed three times with TBST. Serum samples were incubated for one hour at $37^{\circ} \mathrm{C}$. The secondary anti-mouse AP-conjugated immunoglobulins (Sigma-Aldrich, St. Louis, Missouri, USA) were diluted 1:10,000 in TBST supplemented with $0.1 \%$ (w/v) BSA (Sigma-Aldrich, St. Louis, Missouri, USA), added to wells and incubated for one hour at $37^{\circ} \mathrm{C}$. After washing 5 times with TBST, plates were incubated with $1 \mathrm{mg} / \mathrm{ml}$ of p-nitrophenil phosphate in substrate buffer (100 mM glycine, $1 \mathrm{mM} \mathrm{MgCl} 2,1 \mathrm{mM} \mathrm{ZnCl} 2, \mathrm{pH} 10.4$ ) at room temperature in the dark. To stop the reaction, $100 \mu \mathrm{L}$ of $3 \mathrm{M} \mathrm{NaOH}$ was added to each well. Plates were then red in a microplate reader (BioRad model 550) at a wavelength of $405 \mathrm{~nm}$ and analyzed with the Microplate manager 4.0 software (BioRad). Antibody titers were determined at a 1:6,400 serum dilution and were compared between AKR-immunized and control mice by Student's $t$-test with unequal variance $(\mathrm{P}=0.0001)$.

\section{Results}

The $a k r$ gene knockdown resulted in reduced mosquito survival and egg production and increased parasite infection

For the characterization of $a k r$ gene expression in response to parasite infection, adult female mosquitoes were infected with $P$. berghei. Mice were infected with $P$. berghei or left uninfected as control. Twenty-four hours postinfection, adult female mosquitoes were fed on mice to characterize $a k r$ expression in midguts and fat body tissues. To characterize the in vivo effect of $a k r$ knockdown by RNAi on mosquito biology and parasite infection, injection of $a k r$ and unrelated $B 2 m$ control dsRNAs was performed in 600 female mosquitoes fed on 3 different infected mice (200 mosquitoes/mouse). The akr gene mRNA levels were significantly lower in $a k r$ dsRNAinjected mosquitoes when compared to dsRNA controls $(\mathrm{P}<0.05)$ with gene silencing ranging from $16-40 \%$ in the midgut and $25-65 \%$ in the remaining tissues.

The effect of $a k r$ gene knockdown on mosquito mortality, egg production and $P$. berghei infection were characterized. Mosquito survival, evaluated six days after infectious blood meal, was higher in $a k r$ dsRNA-injected mosquitoes when compared to controls (Figure 1A). However, at day-8 postinfectious blood feeding (day 12 post-injection), survival was $14 \%$ lower in mosquitoes with akr gene knockdown (Figure 1A). The $a k r$ gene knockdown also reduced egg production by $52 \%$ when compared to control mosquitoes injected with $B 2 m$ dsRNA (Figure 1B). However, parasite infection, determined by different parameters was higher in mosquitoes with $a k r$ knockdown when compared to controls (Figures 1C-F).

\section{Anti-AKR antibodies reduced $P$. berghei infection in An. gambiae fed on immunized mice}

To evaluate the effect of antibodies against AKR on the malaria vector An. gambiae and the infection with P. berghei, mice were immunized with recombinant mosquito AKR or placebo and infected with $P$. berghei parasites or left uninfected as controls. Mouse antibody titers increased after the first immunization with recombinant AKR and remained significantly higher until the end of the experiment in both AKR-immunized infected and uninfected mice when compared to controls (Figure 2). Different to $a k r$ knockdown, survival was not affected in mosquitoes fed on immunized mice when compared to mosquitoes fed on control mice (Figure 3A). Also in contrast to RNAi results, parasite infection was lower (Figures 3B-D) and egg production was higher (Figures $2 \mathrm{E}$ and $\mathrm{F}$ ) in mosquitoes fed on immunized infected mice when compared to mosquitoes fed on control infected mice. Particularly relevant was the effect on infection intensity, which was reduced in more than 60-fold in mosquitoes fed on immunized mice when compared to controls (Figure 2C). Egg production was significantly lower in mosquitoes fed on immunized uninfected mice when compared to mosquitoes fed on control infected mice (Figure 2E).

\section{Discussion}

The WHO estimates that 207 million cases of malaria and 627,000 deaths occurred globally in 2012. The mosquito An. gambiae is the major vector of parasites causing malaria in sub-Saharan Africa [2]. The increasing prevalence of malaria is attributed to the rapid spread of drugresistant parasites, insecticide-resistant mosquitoes and the absence of a protective vaccine. Our studies were focused on understanding the role of mosquito AKR, a conserved nuclear factor required for innate immune 


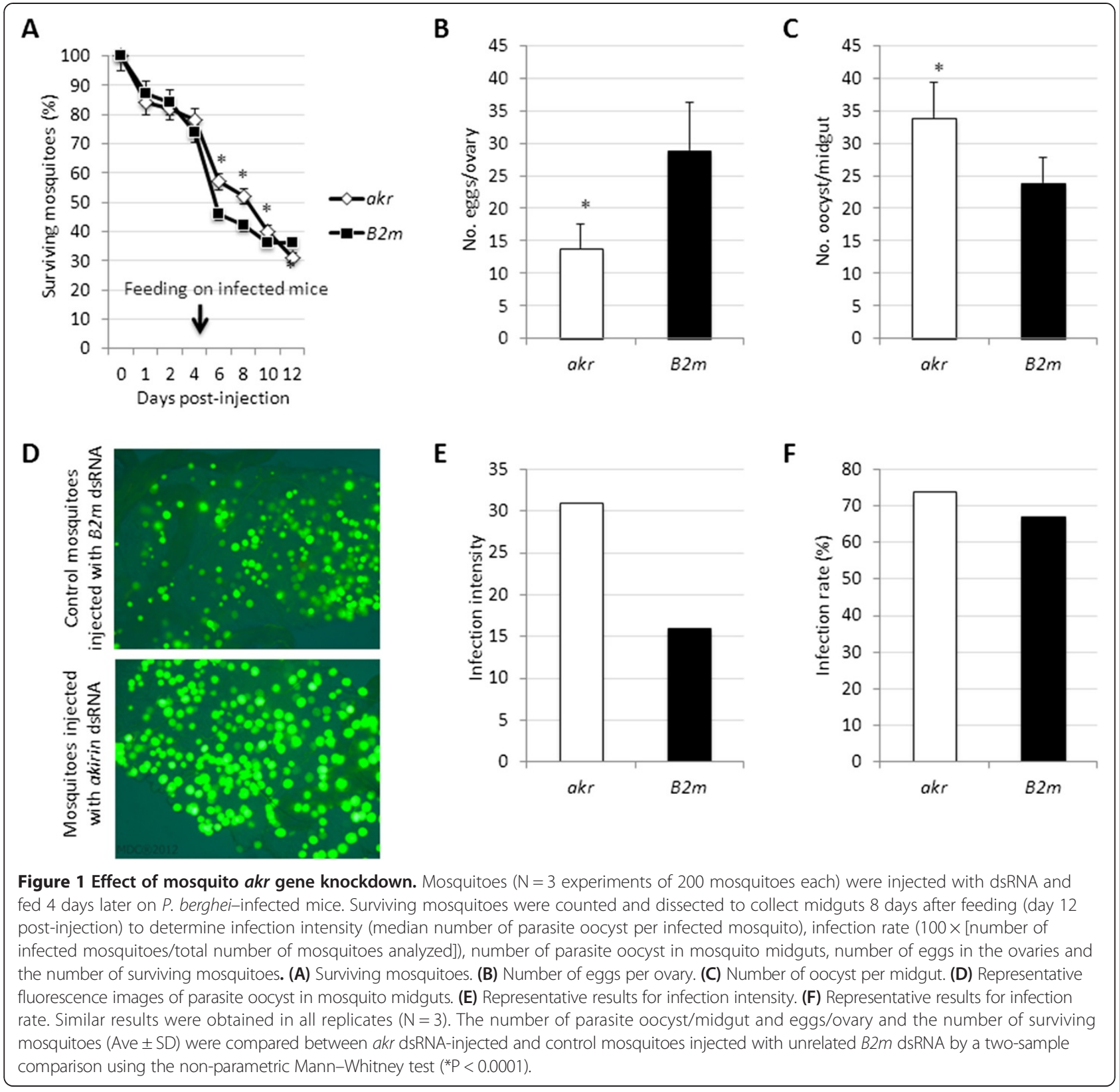

responses, in the complex interactions between the vector and Plasmodium parasite and the potential of this protein as a protective vaccine antigen. As previously shown, tick SUB and mosquito AKR are good protective antigen candidates for the control of both vector infestations and pathogen infection $[15,16,25]$.

RNA interference-based $a k r$ knockdown in mosquitoes was performed as previously reported for other target genes [32]. Obtained data suggests that, as in prior experiments concerning to $a k r / s u b$ RNAi assays in flies [22] and ticks [33-36], mosquito survival and egg production were reduced after gene knockdown, supporting the role of AKR in immune response. RNAi mediated knockdown led to an increase of parasite infection in $A n$. gambiae mosquitos after feeding on infected mice as reported for akr knockdown in flies infected with Agrobacterium tumefasciens [22]. Also in white shrimps (Litopenaeus vannamei) akr mRNA levels are strongly induced in response to Vibrio parahaemolyticus infection and akr silencing lead to high mortality after infection challenge [37]. The effect of $A k r$ silencing on infection level is probably due to the impair of Imd pathway signaling enhancing the sensitivity to bacterial and parasite infection [15,16,22,25]. The increase of Plasmodium parasites levels after gene silencing shows that $\mathrm{AKR} / \mathrm{SUB}$ is required for defense against pathogens and for the regulation of genes that are important for infection. 


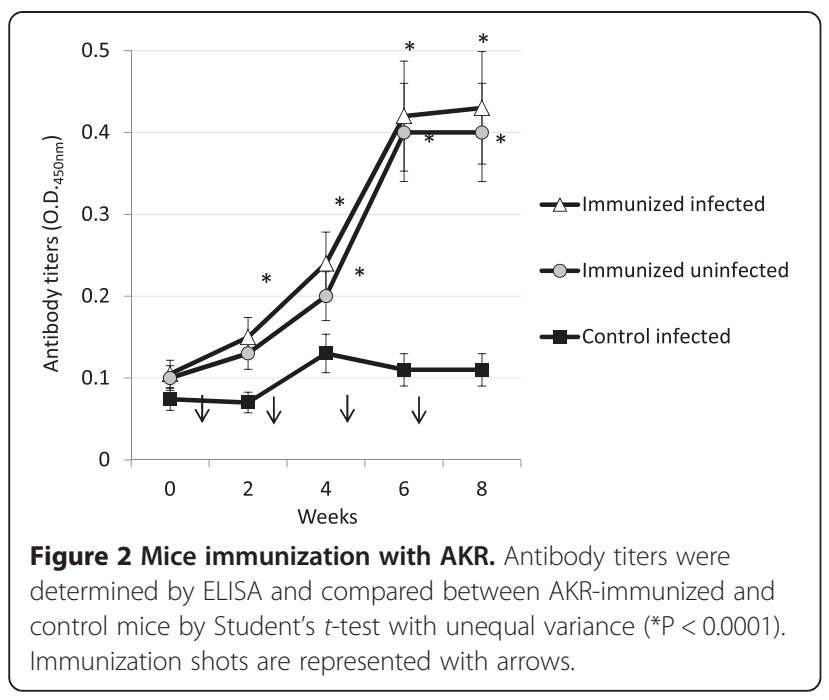

The AKR gene regulation function makes it a potential antigen for vaccine development against vector infestations. Thus, to determine whether AKR could represent a novel target for an An. gambiae infestations control and also to determine its influence on Plasmodium infection process, we vaccinated mice with recombinant AKR from Ae. albopictus.

Following silencing data, AKR vaccination was expected to primarily reduce $A n$. gambiae reproductive and survival parameters since it has been reported that this protein is related not only to the embryonic development of insects [38] or involved in muscle development [39] but also influences infection levels due to its immunity related functions. Previous immunization experiments using this antigen showed a reduction in the oviposition and fertility of Ae. albopictus mosquitoes fed on immunized uninfected mice when compared to controls $[17,18]$.

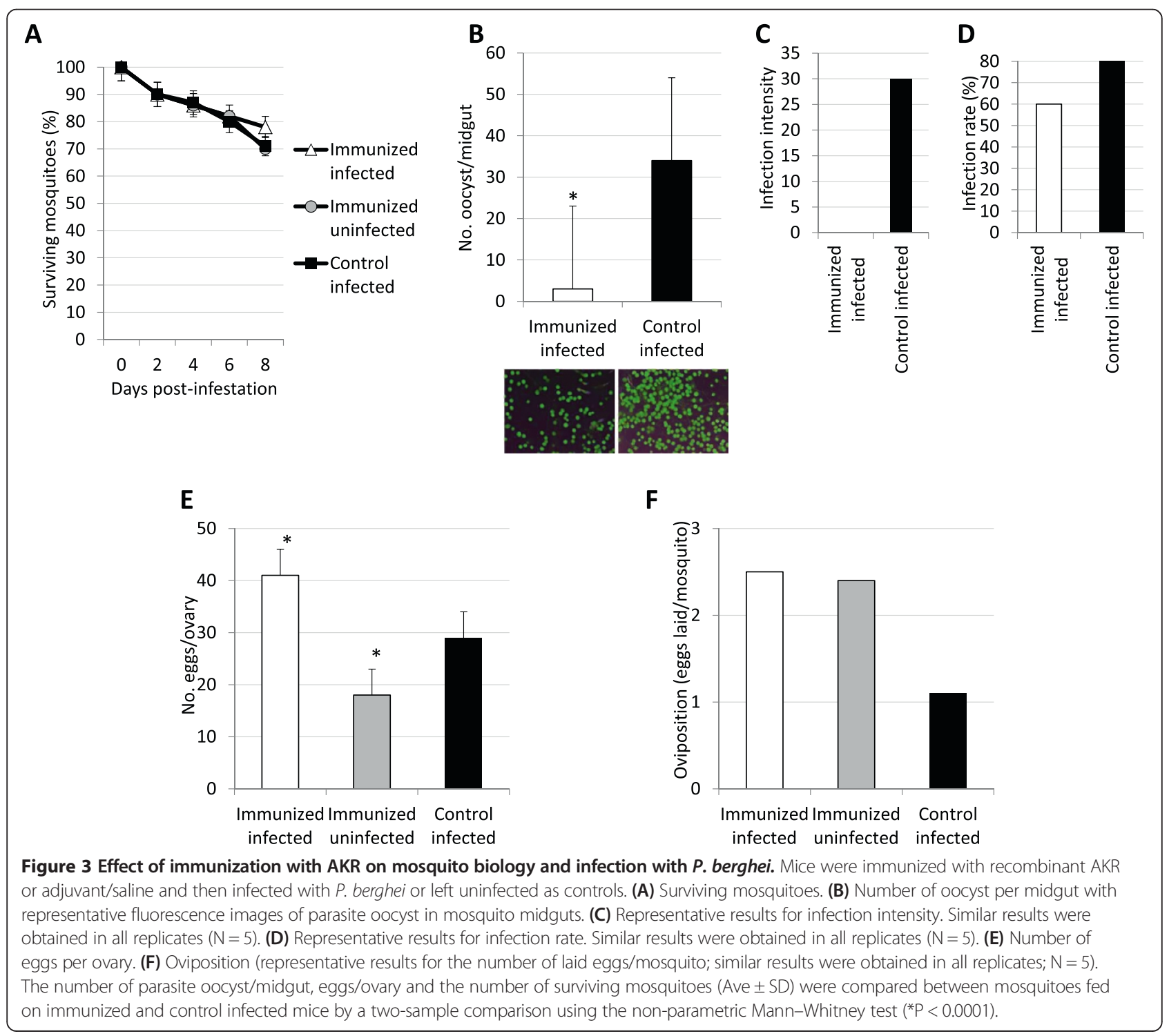


Egg production was also reduced in An. gambiae fed on AKR immunized uninfected mice but AKR did not affect $A n$. gambiae survival after feeding on immunized mice in accordance to other reports $[17,18]$.

Antibodies against recombinant AKR significantly reduced the infection on An. gambiae by P. berghei suggesting that AKR might contribute to the development of vaccines against malaria by reducing parasite infection levels in vector mosquito species. In opposition of what was expected, results suggest that blocking the AKR protein in the cells did not distress Imd pathway but rather we may be targeting protein translocation disturbing, thus, the cell response to infection [25].

The protection elicited by the anti-mosquito vaccine is based on the production antibodies in the vaccinated mice that may interact and affect the function of the target antigen (AKR) leading to a response against Plasmodium proteins. The development of vaccines against bloodsucking arthropod ectoparasites such as mosquitoes is based on the concept that ectoparasites ingest antigenspecific antibodies when feeding on immunized hosts. These antibodies interact with the protective antigen in the arthropod to affect the function and/or quantity of the protein, resulting in reduced survival, reproduction and/or infection with vector-borne pathogens. For SUB/AKR, the mode of action of the antibodies is not completely understood but may be the result of antibodies crossing the cell membrane and interacting with the protein in the cytoplasm to prevent protein translocation to the nucleus $[15,16,25,35,40]$. The issue of vaccine safety with antigens such as AKR that are conserved between invertebrate and vertebrate hosts has been addressed before, suggesting in a low risk to induce autoimmune responses in vertebrate hosts $[17,18,33]$.

\section{Conclusions}

In summary, the results reported here showed that recombinant AKR could be used to develop vaccines for malaria control. If effective, AKR-based vaccines could be used to immunize wildlife reservoir hosts and/or humans to reduce the risk of pathogen transmission.

\section{Competing interests}

The authors declare that they have no competing interests.

\section{Authors' contributions}

JF and AD designed the study. HS designed the mosquito RNAi experiments. $J F, S A$ and $A D$ performed data analysis. MC and RP-S performed the mosquito experiments. MC, RP-S and AC performed molecular work. JAM-C and MV performed recombinant protein production. JF and AD wrote the manuscript. All authors edited and approved the final manuscript.

\section{Acknowledgments}

This research was supported by grant BFU2011-23896 to JF and by funding from the MSc. course on Medical Parasitology from UEIPM-IHMT.

\section{Author details}

${ }^{1}$ Instituto de Higiene e Medicina Tropical, Rua da Junqueira 100, 1349-008 Lisbon, Portugal. ${ }^{2} \mathrm{SaBio}$. Instituto de Investigación en Recursos Cinegéticos IREC, CSIC-UCLM-JCCM, Ronda de Toledo s/n, 13005 Ciudad Recal, Spain. ${ }^{3}$ Department of Veterinary Pathobiology, Center for Veterinary Health Sciences, Oklahoma State University, Stillwater, OK 74078, USA. ${ }^{4}$ Centro de Malária e Outras Doenças Tropicais, Instituto de Higiene e Medicina Tropical, Rua da Junqueira 100, 1349-008 Lisbon, Portugal.

Received: 15 September 2014 Accepted: 27 November 2014

Published: 3 December 2014

\section{References}

1. Jones KE, Patel NG, Levy MA, Storeygard A, Balk D, Gittleman JL, Daszak P: Global trends in emerging infectious diseases. Nature 2008, 451:990-994.

2. WHO: World Malaria Report. Geneva: World Health Organization; 2013.

3. Tyagi RK, Sharma YD: Erythrocyte binding activity displayed by a selective group of Plasmodium vivax tryptophan rich antigens is inhibited by patients' antibodies. PLos One 2012, 7:e50754.

4. Thera MA, Plowe CV: Vaccines for Malaria: How Close Are We? Annu Rev Med 2012, 63:345-357

5. Vekemans J, Leach A, Cohen J: Development of the RTS, S/AS malaria candidate vaccine. Vaccine 2009, 27:G67-G71

6. Brooks A, Briet OJT, Hardy D, Steketee R, Smith TA: Simulated impact of RTS, S/AS01 vaccination programs in the context of changing malaria transmission. Plos One 2012, 7:e32587.

7. Olotu A, Fegan G, Wambua J, Nyangweso G, Awuondo KO, Leach A, Lievens M, Leboulleux D, Njuguna P, Peshu N, Marsh K, Bejon P: Four-year efficacy of RTS, S/AS01E and its interaction with malaria exposure. $N$ Engl J Med 2013, 368:1111-1120.

8. Seder RA, Chang L-J, Enama ME, Zephir KL, Sarwar UN, Gordon IJ, Holman LA, James ER, Billingsley PF, Gunasekera A, Richman A, Chakravarty S, Manoj A, Velmurugan S, Li M, Ruben AJ, Li T, Eappen AG, Stafford RE, Plummer SH, Hendel CS, Novik L, Costner PJ, Mendoza FH, Saunders JG, Nason MC, Richardson JH, Murphy J, Davidson SA, Richie TL, Sedegah M, Sutamihardja A Fahle GA, Lyke KE, Laurens MB, Roederer M, Tewari K, Epstein JE, Sim BK, Ledgerwood JE, Graham BS, Hoffman SL, VRC 312 Study Team: Protection against malaria by intravenous immunization with a nonreplicating sporozoite vaccine. Science 2013, 341:1359-1365.

9. Wu Y, Ellis RD, Shaffer D, Fontes E, Malkin EM, Mahanty S, Fay MP, Narum D, Rausch K, Miles AP, Aebig J, Orcutt A, Muratova O, Song G, Lambert L, Zhu D, Miura K, Long C, Saul A, Miller LH, Durbin AP: Phase 1 trial of malaria transmission blocking vaccine candidates Pfs 25 and Pvs 25 formulated with montanide ISA 51. PLos One 2008, 3:e2636.

10. Lal AA, Patterson PS, Sacci JB, Vaughan JA, Paul C, Collins WE, Wirtz RA Azad AF: Anti-mosquito midgut antibodies block development of Plasmodium falciparum and Plasmodium vivax in multiple species of Anopheles mosquitoes and reduce vector fecundity and survivorship. Proc Natl Acad Sci U S A 2001, 98:5228-5233.

11. Suneja A, Gulia M, Gakhar SK: Blocking of malaria parasite development in mosquito and fecundity reduction by midgut antibodies in Anopheles stephensi (Diptera : Culicidae). Arc Insect Biochem Physiol 2003, 52:63-70.

12. Saul A: Mosquito stage, transmission blocking vaccines for malaria. Curr Opin Infect Dis 2007, 20:476-481.

13. Canales M, Ballesteros C, Moreno-Cid JA, Espinosa AM, Villar M, de la Fuente J: Extractive bioconversion to produce the Aedes albopictus akirin in an aqueous two-phase system supporting Pichia pastoris growth and protein secretion. Biochem Eng J 2009, 46:105-114.

14. Armada A, Gazarini ML, Goncalves LM, Antunes S, Custodio A, Rodrigues A Almeida AJ, Silveira H, do Rosario V, Santos-Gomes G, Domingos A: Generation of an antibody that recognizes Plasmodium chabaudi cysteine protease (chabaupain-1) in both sexual and asexual parasite life cycle and evaluation of chabaupain-1 vaccine potential. Exp Parasitol 2013, 135:166-174.

15. de la Fuente J, Moreno-Cid JA, Galindo RC, Almazan C, Kocan KM, Merino O, de la Lastra JM P, Estrada-Pena A, Blouin EF: Subolesin/Akirin vaccines for the control of arthropod vectors and vectorborne pathogens. Transbound Emerg Dis 2013, 60:172-178.

16. de la Fuente J, Moreno-Cid JA, Canales M, Villar M, de la Lastra JM P, Kocan KM Galindo RC, Almazan C, Blouin EF: Targeting arthropod subolesin/akirin for the development of a universal vaccine for control of vector infestations and pathogen transmission. Vet Parasitol 2011, 181:17-22 
17. Moreno-Cid JA, Jimenez M, Cornelie S, Molina R, Alarcon P, Lacroix M-N, Pinal R, Delacour S, Lucientes J, Canales M, de la Lastra JM P, Villar M, de la Fuente J: Characterization of Aedes albopictus akirin for the control of mosquito and sand fly infestations. Vaccine 2010, 29:77-82.

18. Moreno-Cid JA, de la Lastra JM P, Villar M, Jimenez M, Pinal R, Estrada-Pena A, Molina R, Lucientes J, Gortazar C, de la Fuente J, Grp SAVS: Control of multiple arthropod vector infestations with subolesin/akirin vaccines. Vaccine 2013, 31:1187-1196.

19. Hajdusek O, Sima R, Ayllon N, Jalovecka M, Perner J, de la Fuente J, Kopacek P: Interaction of the tick immune system with transmitted pathogens. Front Cell Infect Microbio/ 2013, 3:26.

20. Torina A, Moreno-Cid JA, Blanda V, de Mera IG F, de la Lastra JMP, Scimeca S, Blanda M, Scariano ME, Briganò S, Disclafani R, Piazza A, Vicente J, Gortázar C, Caracappa S, Lelli RC, de la Fuente J: Control of tick infestations and pathogen prevalence in cattle and sheep farms vaccinated with the recombinant Subolesin-Major Surface Protein 1a chimeric antigen. Parasite Vector 2014, 7:10.

21. Harrington D, Canales M, de la Fuente J, de Luna C, Robinson K, Guy J, Sparagano O: Immunisation with recombinant proteins subolesin and Bm86 for the control of Dermanyssus gallinae in poultry. Vaccine 2009, 27:4056-4063.

22. Goto A, Matsushita K, Gesellchen V, El Chamy L, Kuttenkeuler D, Takeuchi O, Hoffmann JA, Akira S, Boutros M, Reichhart J-M: Akirins are highly conserved nuclear proteins required for NF-kappa B-dependent gene expression in drosophila and mice. Nature Immunol 2008, 9:97-104.

23. Galindo RC, Doncel-Perez E, Zivkovic Z, Naranjo V, Gortazar C, Mangold AJ, Martin-Hernando MP, Kocan KM, de la Fuente J: Tick subolesin is an ortholog of the akirins described in insects and vertebrates. Dev Comp Immunol 2009, 33:612-617.

24. Naranjo V, Ayllon N, de la Lastra JM P, Galindo RC, Kocan KM, Blouin EF, Mitra R, Alberdi P, Villar M, de la Fuente J: Reciprocal Regulation of NF-kB (Relish) and Subolesin in the Tick Vector, Ixodes scapularis. PLos One 2013, 8(6):e65915.

25. Merino O, Alberdi P, Pérez de la Lastra J, de la Fuente J: Tick vaccines and the control of tick-borne pathogens. Front Cell Infect Microbiol 2013, 3:30.

26. Dong Y, Das S, Cirimotich C, Souza-Neto JA, McLean KJ, Dimopoulos G: Engineered Anopheles immunity to Plasmodium infection. PLoS Pathog 2011, 7:e1002458

27. Garver LS, Bahia AC, Das S, Souza-Neto JA, Shiao J, Dong Y, Dimopoulos G: Anopheles Imd pathway factors and effectors in infection intensitydependent anti-Plasmodium action. PLoS Pathog 2012, 8:e1002737.

28. Franke-Fayard B, Trueman H, Ramesar J, Mendoza J, van der Keur M, van der Linden $\mathrm{R}$, Sinden RE, Waters AP, Janse CJ: A Plasmodium berghei reference line that constitutively expresses GFP at a high level throughout the complete life cycle. Mol Biochem Parasitol 2004, 137:23-33.

29. Livak KJ, Schmittgen TD: Analysis of relative gene expression data using real-time quantitative PCR and the 2(T)(-Delta Delta C) method. Methods 2001, 25:402-408.

30. Boisson B, Jacques JC, Choumet V, Martin E, Xu JN, Vernick K, Bourgouin C: Gene silencing in mosquito salivary glands by RNAi. FEBS Lett 2006, 580:1988-1992.

31. Blandin S, Moita LF, Kocher T, Wilm M, Kafatos FC, Levashina EA: Reverse genetics in the mosquito Anopheles gambiae: targeted disruption of the Defensin gene. Embo Rep 2002, 3:852-856.

32. Das S, Radtke A, Choi Y-J, Mendes AM, Valenzuela JG, Dimopoulos G: Transcriptomic and functional analysis of the Anopheles gambiae salivary gland in relation to blood feeding. BMC Genomics 2010, 11:566.

33. Merino O, Almazan C, Canales M, Villar M, Moreno-Cid JA, Estrada-Pena A, Kocan KM, de la Fuente J: Control of Rhipicephalus (Boophilus) microplus infestations by the combination of subolesin vaccination and tick autocidal control after subolesin gene knockdown in ticks fed on cattle. Vaccine 2011, 29:2248-2254.

34. Antunes S, Galindo RC, Almazan C, Rudenko N, Golovchenko M, Grubhoffer L, Shkap V, do Rosario V, de la Fuente J, Domingos A: Functional genomics studies of Rhipicephalus (Boophilus) annulatus ticks in response to infection with the cattle protozoan parasite, Babesia bigemina. Int J Parasitol 2012, 42:187-195.

35. de la Fuente J, Almazan C, Blas-Machado U, Naranjo V, Mangold AJ, Blouin EF, Gortazar C, Kocan KM: The tick protective antigen, 4D8, is a conserved protein involved in modulation of tick blood ingestion and reproduction. Vaccine 2006, 24:4082-4095
36. Nijhof AM, Taoufik A, de la Fuente J, Kocan KM, de Vries E, Jongejan F: Gene silencing of the tick protective antigens, Bm86, Bm91 and subolesin, in the one-host tick Boophilus microplus by RNA interference. Int J Parasitol 2007, 37:653-662.

37. Hou F, Wang X, Qian Z, Liu Q, Liu Y, He S, Mi X, Bai C, Sun C, Liu X: Identification and functional studies of Akirin, a potential positive nuclear factor of NF-KB signaling pathways in the Pacific white shrimp, Litopenaeus vannamei. Dev Comp Immunol 2013, 41:703-714.

38. Nowak SJ, Aihara H, Gonzalez K, Nibu Y, Baylies MK: Akirin links twistregulated transcription with the Brahma chromatin remodeling complex during embryogenesis. PLoS Genet 2012, 8:e1002547.

39. Salerno MS, Dyer K, Bracegirdle J, Platt L, Thomas M, Siriett V, Kambadur R, Sharma M: Akirin1 (Mighty), a novel promyogenic factor regulates muscle regeneration and cell chemotaxis. Exp Cell Res 2009, 315:2012-2021.

40. Merino O, Almazan C, Canales M, Villar M, Moreno-Cid JA, Galindo RC de la Fuente J: Targeting the tick protective antigen subolesin reduces vector infestations and pathogen infection by Anaplasma marginale and Babesia bigemina. Vaccine 2011, 29:8575-8579.

doi:10.1186/1475-2875-13-470

Cite this article as: da Costa et al:: Mosquito Akirin as a potential antigen for malaria control. Malaria Journal 2014 13:470.

\section{Submit your next manuscript to BioMed Central and take full advantage of:}

- Convenient online submission

- Thorough peer review

- No space constraints or color figure charges

- Immediate publication on acceptance

- Inclusion in PubMed, CAS, Scopus and Google Scholar

- Research which is freely available for redistribution

Submit your manuscript at www.biomedcentral.com/submit
C) Biomed Central 